University of Wollongong

Research Online

Faculty of Engineering and Information

Faculty of Engineering and Information

Sciences - Papers: Part A

Sciences

2013

\title{
Changes in surface properties and separation efficiency of a nanofiltration membrane after repeated fouling and chemical cleaning cycles
}

\author{
Alexander Simon \\ University of Wollongong, asimon@uow.edu.au \\ William E. Price \\ University of Wollongong, wprice@uow.edu.au \\ Long D. Nghiem \\ University of Wollongong, longn@uow.edu.au
}

Follow this and additional works at: https://ro.uow.edu.au/eispapers

Part of the Engineering Commons, and the Science and Technology Studies Commons

Research Online is the open access institutional repository for the University of Wollongong. For further information contact the UOW Library: research-pubs@uow.edu.au 


\title{
Changes in surface properties and separation efficiency of a nanofiltration membrane after repeated fouling and chemical cleaning cycles
}

\begin{abstract}
The aim of this study was to evaluate the changes in membrane surface properties and solute separation by a nanofiltration membrane during repetitive membrane fouling and chemical cleaning. Secondary treated effluent and model fouling solutions containing humic acids, sodium alginate, or silica colloids were used to simulate membrane fouling. Chemical cleaning was carried out using a commercially available caustic cleaning formulation. Carbamazepine and sulfamethoxazole were selected to examine the filtration behaviour of neutral and negatively charged organic compounds, respectively. Results show that the impact of membrane fouling on solute rejection is governed by pore blocking, modification of the membrane surface charge, and cake enhanced concentration polarisation. Caustic cleaning was effective at controlling membrane fouling and membrane permeability recovery was slightly more than $100 \%$. In good agreement with the literature, the high membrane permeability recovery observed here suggests that caustic cleaning could lead to temporary enlargement of the membrane pores. In addition, microscopic observations based on scanning electron microscopy and energy dispersive spectroscopy revealed some irreversible fouling on the chemical cleaned membrane. Thus caustic cleaning did not completely remove all foulants from the membrane surface and the membrane surface hydrophobicity and zeta potential changed correspondingly. The temporary enlargement of the membrane pores due to caustic cleaning subsequently led to notable changes in the rejection of inorganic salts (measured by conductivity) and carbamazepine. By contrast, the impact of chemical cleaning on the rejection of the negatively charged sulfamethoxazole was negligible. This is because the rejection of sulfamethoxazole is predominantly governed by electrostatic repulsion between the compound and the negatively charged membrane surface and thus is not significantly influenced by any enlargement of the membrane pores.
\end{abstract}

\section{Keywords}

surface, properties, repeated, separation, efficiency, fouling, nanofiltration, cleaning, membrane, chemical, changes, cycles, after

\section{Disciplines}

Engineering | Science and Technology Studies

\section{Publication Details}

Simon, A., Price, W. E. \& Nghiem, L. D. (2013). Changes in surface properties and separation efficiency of a nanofiltration membrane after repeated fouling and chemical cleaning cycles. Separation and Purification Technology, 113 42-50. 


\title{
Changes in Surface Properties and Separation Efficiency of a Nanofiltration Membrane after Repeated Fouling and Chemical Cleaning Cycles
}

\author{
Revised Fresh Manuscript Submitted to \\ Separation Purification Technology
}

April 2013

Alexander Simon ${ }^{1}$, William E. Price ${ }^{2}$, Long D. Nghiem ${ }^{1, *}$

${ }^{1}$ School of Civil Mining and Environmental Engineering

The University of Wollongong, Wollongong, NSW 2522, Australia

${ }^{2}$ School of Chemistry

The University of Wollongong, Wollongong, NSW 2522, Australia

* Corresponding author: Long D. Nghiem, Email longn@uow.edu.au; Tel: +61 242214590 


\begin{abstract}
The aim of this study was to evaluate the changes in membrane surface properties and solute separation by a nanofiltration membrane during repetitive membrane fouling and chemical cleaning. Secondary treated effluent and model fouling solutions containing humic acids, sodium alginate, or silica colloids were used to simulate membrane fouling. Chemical cleaning was carried out using a commercially available caustic cleaning formulation. Carbamazepine and sulfamethoxazole were selected to examine the filtration behaviour of neutral and negatively charged organic compounds, respectively. Results show that the impact of membrane fouling on solute rejection is governed by pore blocking, modification of the membrane surface charge, and cake enhanced concentration polarisation. Caustic cleaning was effective at controlling membrane fouling and membrane permeability recovery was slightly more than $100 \%$. In good agreement with the literature, the high membrane permeability recovery observed here suggests that caustic cleaning could lead to temporary enlargement of the membrane pores. In addition, microscopic observations based on scanning electron microscopy and energy dispersive spectroscopy revealed some irreversible fouling on the chemical cleaned membrane. Thus caustic cleaning did not completely remove all foulants from the membrane surface and the membrane surface hydrophobicity and zeta potential changed correspondingly. The temporary enlargement of the membrane pores due to caustic cleaning subsequently led to notable changes in the rejection of inorganic salts (measured by conductivity) and carbamazepine. By contrast, the impact of chemical cleaning on the rejection of the negatively charged sulfamethoxazole was negligible. This is because the rejection of sulfamethoxazole is predominantly governed by electrostatic repulsion between the compound and the negatively charged membrane surface and thus is not significantly influenced by any enlargement of the membrane pores.
\end{abstract}

Keywords: Nanofiltration, pharmaceutically active compounds (PhACs), membrane fouling, caustic cleaning. 


\section{Introduction}

Water reuse (or recycling) has been recognised as an important strategy to address the issue of clean water scarcity. Several in-direct potable water reuse schemes are currently in operation around the world [1-2]. These schemes use the multiple barrier approach involving a series of integrated treatment processes. In a typical treatment train for water reuse applications, secondary treated effluent is further purified by nanofiltration (NF) or reverse osmosis (RO) membrane filtration followed by UV oxidation, with or without peroxide. The NF/RO filtration process plays a major role for the removal of pharmaceutically active compounds (PhACs) that occur ubiquitously in secondary treated effluent [3]. PhACs can adversely affect human health and the environment and therefore, they must be removed by NF/RO membranes and other advanced treatment processes [3-5]. An inherent problem associated with the use of NF/RO membranes is fouling and the required chemical cleaning process [6]. Membrane fouling and chemical cleaning can not only increase the operating costs but also compromise the quality of the treated water [6]. Membrane fouling occurs through the deposition of organic and inorganic matter and/or the formation of biofilm on the membrane surface, leading to a decline in the membrane permeability. In water reuse applications, prevalent forms of NF/RO membrane fouling include both organic and colloidal fouling [7]. The fouling process involves chemical and physical interactions between the foulants and the membrane polymeric surface, which are influenced by the feed temperature and feed solution chemistry [7]. Depending on the physicochemical properties of the solute and the membrane, feed solution chemistry and nature of the fouling layer may either result in an increase or decrease in PhAC rejection [8-10]. Membrane fouling can restrict the membrane pores due to pore blocking or internal foulant adsorption, leading to a decrease in the convective solute transport through the membrane pores [9]. By contrast, the cake layer may hinder the back diffusion of solutes away from the membrane surface, leading to an enhanced concentration polarisation phenomenon and reduced solute rejection [11-13]. In addition, membrane fouling can affect charge and hydrophobic solute-membrane interactions [9, 12, 1416]. Subsequent chemical cleaning to restore the membrane flux can result in the adsorption of cleaning additives and/or cause conformational changes of the membrane polymer, which can further affect the PhAC rejection [17-20].

In full-scale applications, where NF/RO membranes experience many repetitive fouling-cleaning cycles, both membrane fouling and chemical cleaning can simultaneously affect the membrane 
properties and therefore, the solute rejection. However, there is a paucity of research on the impact of repetitive membrane fouling and chemical cleaning cycles on $\mathrm{PhAC}$ rejection. The available literature is scarce and sometimes inconsistent. Košutić and Kunst [21] observed that humic acid fouling led to a decrease in salt rejection. They also reported that subsequent alkaline cleaning could restore the salt rejection, while a delay in chemical cleaning could lead to a further decrease in rejection [21]. In another study, Wei et al. [22] reported that the fouling of an NF membrane by wastewater from a pharmaceutical factory had no impact on salt rejection, whereas, subsequent caustic or acidic cleaning led to considerable decrease or increase in rejection, respectively. On the other hand, Klüpfel and Frimmel [23] reported no significant variation in $\mathrm{PhAC}$ rejection due to membrane fouling by surface water and subsequent caustic cleaning.

The aim of this study was to investigate the impact of repetitive membrane fouling and chemical cleaning on the rejection of PhACs by an NF membrane. Membrane fouling was simulated using secondary treated effluent and model fouling solutions containing humic acids, sodium alginate, or silica colloids. Chemical cleaning was carried out using a commercially available caustic cleaning formulation. The morphology of the fouled and chemically cleaned membranes was examined by scanning electron microscopy and energy dispersive spectroscopy (SEM-EDS). The changes in conductivity and $\mathrm{PhAC}$ rejection caused by membrane fouling and the subsequent chemical cleaning were related to the changes in membrane permeate flux, surface charge and hydrophobicity to elucidate the mechanisms involved.

\section{Materials and Methods}

\subsection{Representative Membrane}

A thin-film composite NF270 membrane (Dow FilmTec, Minneapolis, MN, USA) was used in this study. This is a semi-aromatic piperazine based polyamide nanofiltration membrane with an estimated average pore size of $0.84 \mathrm{~nm}$ and pure water permeability of $13.5 \mathrm{~L} / \mathrm{m}^{2} \mathrm{hbar}$ [24]. The recommended operational $\mathrm{pH}$ range is between $\mathrm{pH} 3$ and 10 with a maximum operating temperature of $45{ }^{\circ} \mathrm{C}$. However, the manufacturer also specifies a maximum operating temperature of $35^{\circ} \mathrm{C}$ when the feed solution $\mathrm{pH}$ exceeds $\mathrm{pH} 10$. According to the manufacturer, strong acidic $(\mathrm{pH} \mathrm{1)}$ and caustic $(\mathrm{pH}$ 12) solutions can be used for cleaning procedures of 30 minutes or less [25]. 


\subsection{Representative Trace Organics}

Analytical grade sulfamethoxazole and carbamazepine were used in this study to investigate the behaviour of negatively charged and neutral PhACs, respectively. Sulfamethoxazole is a negatively charged compound due to its protonation above $\mathrm{pH}$ 5.8. By contrast, carbamazepine can only exist as a neutral species in the environmental $\mathrm{pH}$ range (i.e. $\mathrm{pH} 3$-10). The molecular weight of sulfamethoxazole and carbamazepine is $253.3 \mathrm{~g} / \mathrm{mol}$ and $236.3 \mathrm{~g} / \mathrm{mol}$, respectively. Both compounds are hydrophilic and are not expected to adsorb to the membrane polymeric matrix. Both compounds were purchased from Sigma Aldrich (Castle Hill, NSW, Australia) and a stock solution was prepared by diluting $1 \mathrm{~g} / \mathrm{L}$ of each compound in methanol. The stock solution was stored in a freezer at $-18^{\circ} \mathrm{C}$ and used within one month.

\subsection{Membrane Foulants}

\subsubsection{Selected Model Foulants}

Humic acid, Ludox HS30 silica colloidal and sodium alginate were used to simulate soluble humic substances, colloidal particles and polysaccharides that are ubiquitous in secondary treated effluent. These model foulants were purchased from Sigma Aldrich (Castle Hill, NSW, Australia). The Ludox HS30 was supplied as a 30\% (w/w) suspension in water. The hydrodynamic diameter of the Ludox HS30 silica colloids was estimated to be approximately $9 \mathrm{~nm}$ [26]. By contrast, molecular weights of the humic acid and sodium alginate were in a range $12-80$ and $1-100$ $\mathrm{kDa}$, respectively [27].

\subsubsection{Secondary Treated Effluent}

Secondary treated effluent was employed to simulate a fouling condition typical to real water reuse applications using NF/RO membrane filtration. The secondary treated effluent was obtained from a sewage treatment plant in New South Wales, Australia. The properties and chemistry of this water are summarised in Table 1. Cations and anions were analysed with an Agilent model 7500CS (Agilent Technologies, Wilmington, DE, USA) inductively coupled plasma - mass spectrometry (ICP-MS) and a Shimadzu ion chromatography (IC, Shimadzu, Tokyo, Japan), respectively. The details of these ICP-MS and IC analyses are available elsewhere [27].

Table 1: Characteristics of the secondary treated effluent

General properties 


\begin{tabular}{|l|c|}
\hline Total organic carbon (TOC) & $14.79 \mathrm{mg} / \mathrm{L}$ \\
\hline Conductivity & $1132 \mu \mathrm{S} / \mathrm{cm}$ \\
\hline Turbidity & $5.78 \mathrm{NTU}$ \\
\hline $\mathrm{pH}$ & 6.8 \\
\hline \hline \multicolumn{2}{|c|}{ Major anions and cations $(\mathrm{mg} / \mathrm{L})$} \\
\hline $\mathrm{Cl}^{-}$ & 179.3 \\
\hline $\mathrm{SO}_{4}^{2-}$ & 42.1 \\
\hline $\mathrm{NO}_{3}^{-}$ & 14.4 \\
\hline $\mathrm{Na}^{+}$ & 96.8 \\
\hline $\mathrm{Ca}^{2+}$ & 18.6 \\
\hline $\mathrm{Mg}^{2+}$ & 10.7 \\
\hline $\mathrm{K}^{+}$ & 16.9 \\
\hline
\end{tabular}

\subsection{Membrane Cleaning Reagent}

The commercially available caustic cleaning formulation MC11 (IMCD, Mulgrave, Victoria, Australia) was selected in this study due to its ability to treat various types of organic foulants [28]. MC11 was supplied in powder form and a chemical cleaning solution was prepared following the manufacturer recommendations by dissolving $25 \mathrm{~g} / \mathrm{L}$ MC11 in Milli-Q water, resulting in a clear liquid with a $\mathrm{pH}$ of 11.2 at $20 \pm 1{ }^{\circ} \mathrm{C}$. According to the manufacturer, MC11 is a blend of detergent builders, $\mathrm{pH}$ buffer and contains the metal chelaters ethylenediaminetetraacetic acid (EDTA), sodium tripolyphosphate (SDP) and trisodium phosphate (TSP). The exact concentrations of these ingredients are unknown.

\subsection{Filtration Setup and Protocol}

A laboratory-scale stainless steel cross-flow NF/RO filtration system was used and consisted of a flat-sheet membrane cell with an effective surface area of $40 \mathrm{~cm}^{2}(4 \mathrm{~cm} \times 10 \mathrm{~cm})$, a stainless steel feed reservoir and a high-pressure pump (Hydra-cell, Wanner Engineering Inc. Minneapolis, MN, USA). The concentrate and permeate flows were monitored by a rotameter (MPB Industries, Tonbridge, Kent, UK) and a digital flowmeter (Model 5025000, GJC Instruments Ltd., UK). Feed pressure and cross-flow velocity were controlled with a by-pass valve and a back-pressure regulator. The temperature of the feed was maintained using a PID control chiller (Neslab RTE7, Thermo Fisher Scientific, Canada). Both the concentrate and permeate were recirculated back into the feed reservoir during the experiment. Prior to each filtration experiment, the membrane was compacted at 18 bar using Milli-Q water overnight. The fouling and chemical cleaning experiments were then conducted as follows (Figure 1). 


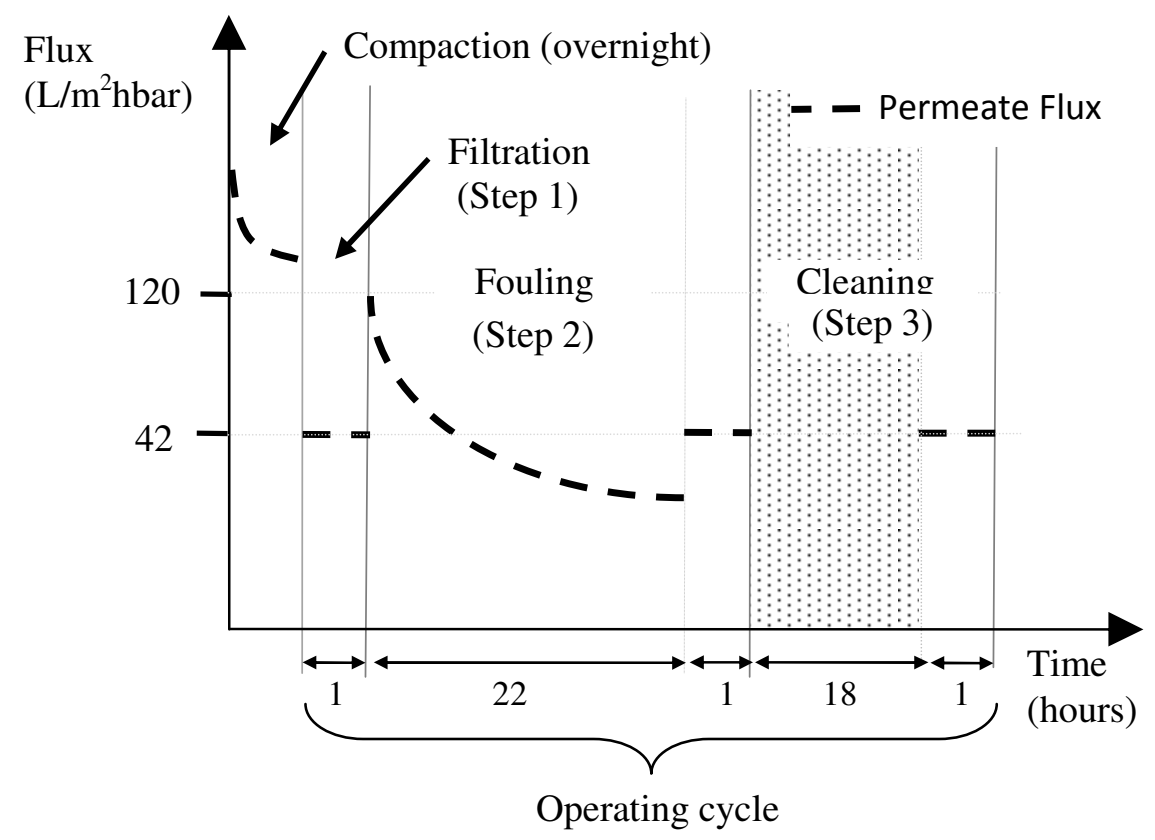

Figure 1: Schematic diagram of the membrane permeate flux regime during one cycle of operation.

Step 1: The Milli-Q water was replaced with 10 litre of an electrolyte solution ( $\mathrm{pH} 8$ ) containing $1 \mathrm{mM} \mathrm{CaCl}_{2}, 20 \mathrm{mM} \mathrm{NaCl}, 1 \mathrm{mM} \mathrm{NaHCO}_{3}$ to represent the ionic strength of secondary effluent. Subsequently, $750 \mu \mathrm{g} / \mathrm{L}$ of each carbamazepine and sulfamethoxazole was added to the background electrolyte. The system was stabilized for one hour at a permeate flux of $42 \mathrm{~L} / \mathrm{m}^{2} \mathrm{~h}$ (which is similar to the nominal permeate flux of the NF270 membrane) and cross-flow velocity of $23.6 \mathrm{~cm} / \mathrm{s}$. Subsequently, feed and permeate samples were collected to determine the rejection of PhACs and conductivity.

Step 2: The membrane permeate flux was then adjusted to $120 \mathrm{~L} / \mathrm{m}^{2} \mathrm{~h}$ and membrane fouling was initiated by adding a model foulant (i.e. humic acid, silica colloids or sodium alginate at $20 \mathrm{mg} / \mathrm{L}$ ) into the feed solution. Membrane fouling was allowed to develop for 22 hours. The permeate flux and cross-flow velocity were then adjusted to $42 \mathrm{~L} / \mathrm{m}^{2} \mathrm{~h}$ and $23.6 \mathrm{~cm} / \mathrm{s}$, respectively, and the rejection of PhACs and conductivity were measured again after stabilizing the system for one hour as in Step 1.

Step 3: Following the membrane fouling step, the model fouling solution was replaced with 4 litres of the cleaning reagent MC11. Chemical cleaning of the fouled membrane was carried out by blocking the permeate outlet and circulating the solution for 18 hours at a cross-flow velocity 
of $70 \mathrm{~cm} / \mathrm{s}$. Subsequently the cleaning solution was removed, and the system rinsed with a copious amount of Milli-Q water. The chemically cleaned membrane was operated using an identical background electrolyte solution as previously described in Step 1. The rejection values of PhACs and conductivity as well as the permeate flux after chemical cleaning were measured again after stabilizing the system for one hour as in Step 1.

Steps 1-3 were repeated to simulate another fouling/chemical cleaning cycle. The temperature of the feed and cleaning solutions was kept at $20 \pm 0.1{ }^{\circ} \mathrm{C}$ in all experiments. When the secondary treated effluent was used to simulate fouling, the experiments were performed using the same protocol as described above using the secondary treated effluent solution instead of the synthetic fouling solution. In addition, the background electrolyte solution used to measure the permeability and rejection of virgin and cleaned membrane was modified to match with the ionic strength and $\mathrm{pH}$ of the secondary effluent. The electrolyte solution used in step 1 for a model foulant was diluted with Milli-Q water and the solution $\mathrm{pH}$ was adjusted using $\mathrm{HCl}$. The fouled membrane flux ratio $(F F R)$, flux recovery (Flux $R e c$ ) and rejection $(R)$ are calculated as below.

$\operatorname{FFR}(\%)=\left(\frac{J_{a f}}{J_{\text {virgin }}}\right) \times 100$

Eq. 1

$\operatorname{Flux} \operatorname{Rec}(\%)=\left(\frac{J_{a c}}{J_{\text {virgin }}}\right) \times 100$

Eq. 2

$\mathrm{R}(\%)=\left(1-\frac{C_{p}}{C_{f}}\right) \times 100$

Where $J_{\text {virgin }}$ is the virgin membrane permeate flux and $J_{\text {af }}$ and $J_{\text {ac }}$ is the permeate flux after fouling and cleaning, respectively. $C_{p}$ and $C_{f}$ are the concentration in the permeate and feed solution, respectively.

The fouling and cleaning cycles simulated in this study differs from that in full-scale applications, where membrane fouling tends to occur over several weeks or months and chemical cleaning is usually conducted when the flux decline has reached approximately 10\% [29]. However, because the impact of fouling on rejection is governed by the interaction among the foulant, membrane and solute, the fouling simulation protocol adapted here is representative of a typical full-scale application. Similar fouling simulation protocols have been used in other studies [8, 12-13, 30]. It 
is also noteworthy that the cleaning protocol adapted here aimed to simulate a cleaning event for a severely fouled membrane [31].

\subsection{Membrane Characterisation Measurements}

\subsubsection{Contact angle}

Contact angle measurements of the virgin, fouled and chemically cleaned membrane samples were performed with a Rame-Hart Goniometer (Model 250, Rame-Hart, Netcong, NJ) using the standard sessile drop method. Membrane samples were dried under a gentle stream of instrument grade air prior to the measurement with Milli-Q water as the reference solvent. At least five droplets were applied to each membrane sample and the contact angle was measured on both sides of the droplet.

\subsubsection{Zeta Potential}

The streaming potential of the membrane surface was determined using a SurPASS Electrokinetic Analyser (Anton Paar GmbH, Graz, Austria). Prior to the streaming potential, samples of virgin, cleaned and fouled membranes were soaked for 24 hours in Milli-Q water and rinsed gently with copious amounts of Milli-Q water. This procedure was adopted to prevent the fouling layer from being sheared away from the membrane surface, thus, allowing stable streaming potential measurement conditions. However, this procedure might result in some chemical and/or physical modifications of the fouling layer. All streaming potential measurements were performed in a $1 \mathrm{mM} \mathrm{KCl}$ background solution, at $500 \mathrm{mbar}$ and at room temperature $\left(25 \pm 1^{\circ} \mathrm{C}\right)$. Analytical grade hydrochloric acid $(1 \mathrm{M})$ and potassium hydroxide $(1 \mathrm{M})$ was used to adjust the $\mathrm{pH}$ of the $\mathrm{KCl}$ solution by automatic titration. Measurements were performed four times at each $\mathrm{pH}$ and the calculated error was less than $1 \mathrm{mV}$. The zeta potential was calculated from the measured streaming potential using the Fairbrother-Mastin approach.

\subsubsection{Scanning Electron Microscopy and Energy Dispersive Spectroscopy}

SEM-EDS analysis of the membrane surface was conducted using a JSM-6490LA Electron Microscopy (JEOL, Tokyo, Japan). Prior to the analysis, the membrane samples were coated with a thin layer of carbon using a carbon sputter (SPI Module, West Chester, PA, USA). Images of fouled and chemically cleaned NF270 membrane samples were taken at 15,000 times magnification, $20 \mathrm{KV}$ and the spotsize of $40 \mathrm{~nm}$. Energy dispersive spectrometry was conducted (EDAX, Mahwah, NJ, USA) at 2,000 times magnification, at $15 \mathrm{kV}$ and the spotsize of $55 \mathrm{~nm}$. 


\subsection{Analytical methods}

A high-pressure liquid chromatograph (Shimadzu HPLC system, Kyoto, Japan) equipped with a Discovery C18 column (with diameter, length and pore size of $4.6 \mathrm{~mm}, 300 \mathrm{~mm}$ and $5 \mu \mathrm{m}$, respectively) was used to analyse for sulfamethoxazole and carbamazepine. The detection method was UV-Vis (Model SPD-10Avp) at a wavelength of $280 \mathrm{~nm}$. The mobile phase was prepared using HPLC grade acetonitrile (ACN) and an aqueous $\mathrm{KH}_{2} \mathrm{PO}_{4}(25 \mathrm{mM})$ buffer solution and designated as eluent A (80\% ACN and 20\% buffer solution) and eluent B (20\% ACN and $80 \%$ buffer solution). The sample injection volume and flow rate were $50 \mu \mathrm{L}$ and $1 \mathrm{~mL} / \mathrm{min}$, respectively. The detection uncertainty was $0.64 \%$ for sulfamethoxazole and $0.39 \%$ for carbamazepine at a concentration of $750 \mu \mathrm{g} / \mathrm{L}$ [19]. The detection limit for both compounds in this condition was approximately $20 \mu \mathrm{g} / \mathrm{L}$. The analysis was carried out immediately after the filtration experiment.

\section{Results and Discussion}

\subsection{Membrane fouling and permeate flux recovery}

NF270 is a loose NF membrane [24, 32]. As a result, the permeate flux decline caused by organic fouling (i.e. humic acid, sodium alginate, and secondary treated effluent) appeared to occur in two separate phases, as reported in a previous study [33]. The initial phase involved pore blocking, which resulted in a rapid decline in the membrane permeate flux (Figure 2). In the second phase, the permeate flux decline became gradual which could be attributed to the build-up of an organic fouling layer on the membrane surface. By contrast, the permeate flux decline due to silica colloidal fouling was less severe than by organic fouling (Figure 2). The hydrodynamic diameter of the silica colloids (9 nm [26]) used in this study was significantly larger than the average pore diameter of the NF270 membrane (0.84 nm [24]). Therefore, adsorption or pore blocking of the membrane surface due to silica colloidal fouling would be negligible. The gradual flux decline due to silica colloidal fouling observed in Figure 2 may be attributed to the build-up of a colloidal cake layer on the membrane surface.

The permeate flux decline profiles due to organic fouling differ slightly between virgin and chemically cleaned membranes (Figure 2). This is likely due to the alteration of the membrane surface roughness and hydrophobicity caused by chemical cleaning [19, 34]. In fact, while these variations (Figure 2) may not be statistically significant, changes in the membrane surface 
properties and separation efficiency due to chemical cleaning are quite significant, as it will be discussed further in the subsequent sections. On the other hand, no significant disparity in permeate flux decline due to silica colloidal fouling between the two operation cycles could be observed. As discussed above, membrane fouling caused by the relative large size of the silica colloids was due to the formation of the colloidal cake layer on the membrane surface. Consequently, the fouling process was not significantly influenced by the membrane physicochemical properties.

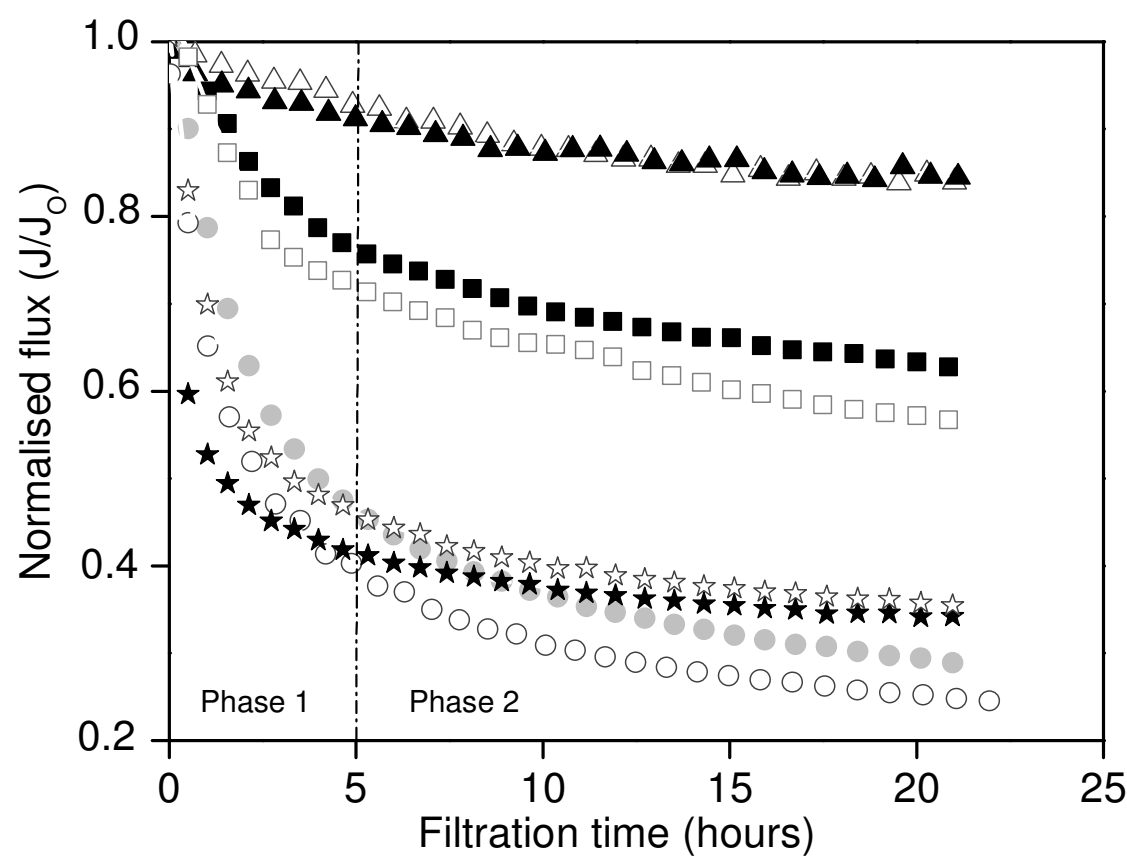

Humic acid

- Cycle 1

○ Cycle 2

Silica colloids

- Cycle 1

$\triangle$ Cycle 2

\section{Sodium alginate \\ $\star \quad$ Cycle 1 \\ « Cycle 2}

\section{Secondary treated}

effluent

- Cycle 1

$25 \square$ Cycle 2

Figure 2: Permeate flux as a function of time during fouling development. The feed $(10 \mathrm{~L})$ was secondary treated effluent or a solution containing $1 \mathrm{mM} \mathrm{CaCl}_{2}, 20 \mathrm{mM} \mathrm{NaCl}, 1 \mathrm{mM} \mathrm{NaHCO}$ and $20 \mathrm{mg} / \mathrm{L}$ of model foulant (i.e. humic acid, silica colloids or sodium alginate). Fouling development was started at permeate flux of $120 \mathrm{~L} / \mathrm{m}^{2} \mathrm{~h}$. The cross-flow velocity and temperature during the fouling process were $23.6 \mathrm{~cm} / \mathrm{s}$ and $20.0 \pm 0.1{ }^{\circ} \mathrm{C}$, respectively. After each fouling process, subsequent caustic cleaning was carried out for 18 hours.

Under all fouling conditions, flux recovery using the MC11 formulation was higher than that of the virgin membrane (Figure 3), which is consistent with our previous work [19]. In addition, Liikanen et al. [20] also reported that caustic chelating reagents in combination with a caustic cleaner resulted in the best membrane cleaning efficiency with respect to both flux recovery and foulant removal. Caustic formulated cleaning is effective in the removal of organic foulants as it 
enhances the charge repulsion of negatively charged foulants from the deprotonated membrane surface. In addition, alkaline metal chelating reagents, such as EDTA, have a strong chelating ability, which disrupt intermolecular foulant-cation bridges and thus, supports the opening of the organic foulant layer. The strong caustic solution can emulsify the foulants and hydrolyses proteins and polysaccharides [29]. Furthermore, charge repulsion between the membrane polymeric functional groups can also result in the enlargement of the membrane pores and/or an increase in the porosity of the membrane skin layer. Membrane interaction with alkaline cleaning detergents, such as EDTA, can further aggravate this effect [20]. Due to hysteresis, the membrane porosity does not immediately return to its normal condition when the caustic cleaning solution is replaced by an aqueous feed solution at near neutral $\mathrm{pH}$. Consequently, following caustic cleaning, the membrane permeate flux observed can be higher than that of a virgin membrane [34]. A similar observation was also reported in a previous study [34], when the virgin NF270 membrane was directly exposed to the MC11 cleaning formulation.

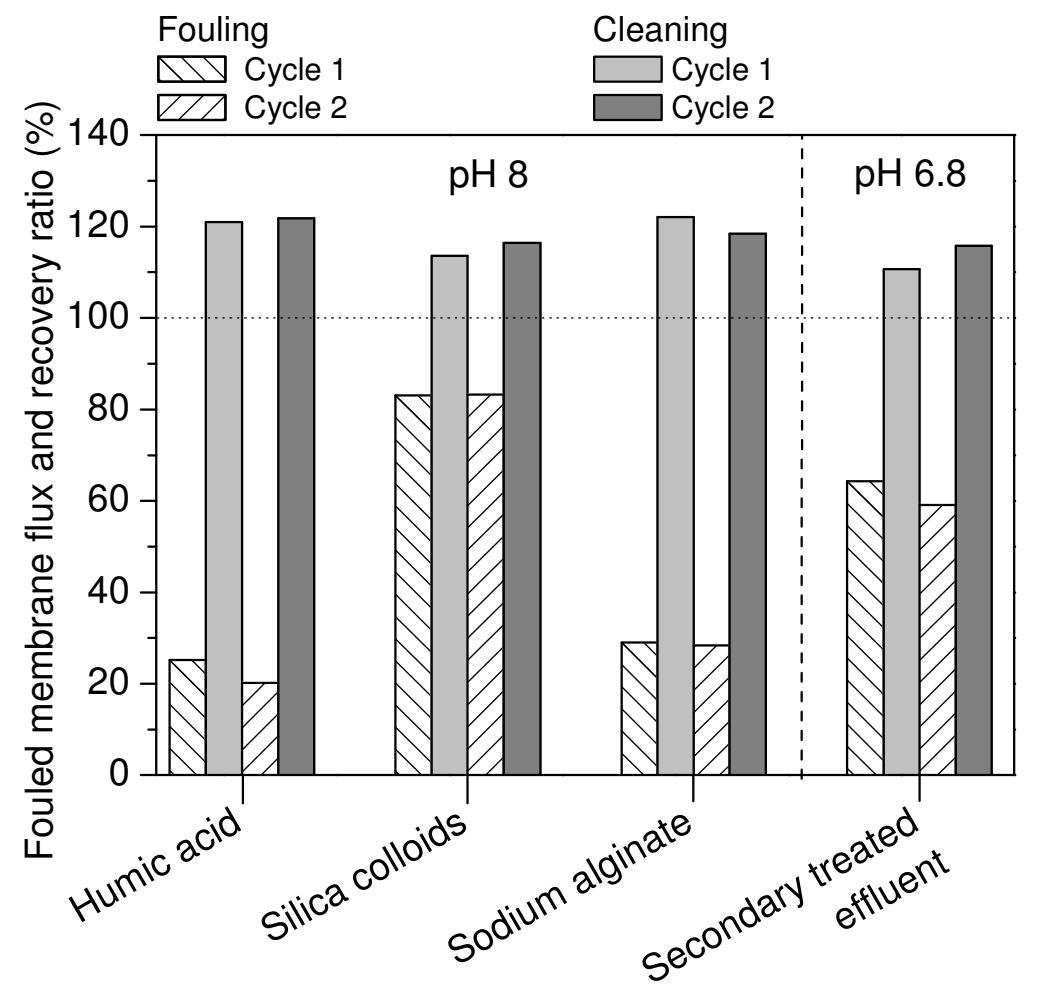

Figure 3: Normalised post fouling and cleaning flux. The fouling conditions were as in Figure 2. Chemical cleaning was performed for 18 hours at $\mathrm{pH}$ 11.2. Cross-flow velocity and temperature during chemical cleaning were $70 \mathrm{~cm} / \mathrm{s}$ and $20 \pm 0.1^{\circ} \mathrm{C}$, respectively. 


\subsection{Impact on Membrane Surface Properties}

\subsubsection{Surface Morphology}

Membrane fouling caused by humic acids, sodium alginate, secondary treated effluent, and silica colloids resulted in the fouling layer covering the entire membrane surface (Figure 4). In good agreement with the changes in the permeate flux observed in Figure 3, humic acid, sodium alginate, and secondary treated effluent resulted in a dense fouling layer, whereas, the silica colloidal fouling layer was quite porous (Figure 4). Caustic cleaning removed most of the foulants from the membrane surface (Figure 4). However, it was also observed that the removal of foulants from the membrane surface was not complete. Indeed, SEM micrographs of the chemically cleaned membrane showed granular-like features on the membrane surface (Figure 4). It is noteworthy that the virgin NF270 has a very smooth surface and these granular-like features were not observed on the virgin NF270 membrane (data not shown). Thus, these granular-like features are likely to be foulant residues on the membrane surface and/or caused by an increase in surface roughness as a response to caustic chemical cleaning.

In good agreement with the SEM micrographs, EDS data of the fouled and cleaned NF270 membrane surfaces differ distinctively from each other (Figure 4). Carbon, oxygen, and sulphur were identified as the main elements of the virgin NF270 (data not shown) and membrane fouling added further characteristic key elements such as silica and calcium of the corresponding foulants. It is important to note the large calcium peak obtained from the humic acid and sodium alginate, since calcium accelerates and aggravates organic fouling by complexing with the organic molecules [30] (Figure 4a and c). The incomplete foulant removal by the chemical cleaning procedure used is also supported in the EDS data (Figure 4). Trace amounts of silica and calcium were found on the membrane surface after the membrane was fouled by silica colloidal and secondary treated effluent and then cleaned with the MC11 reagent (Figure 4b and d). 

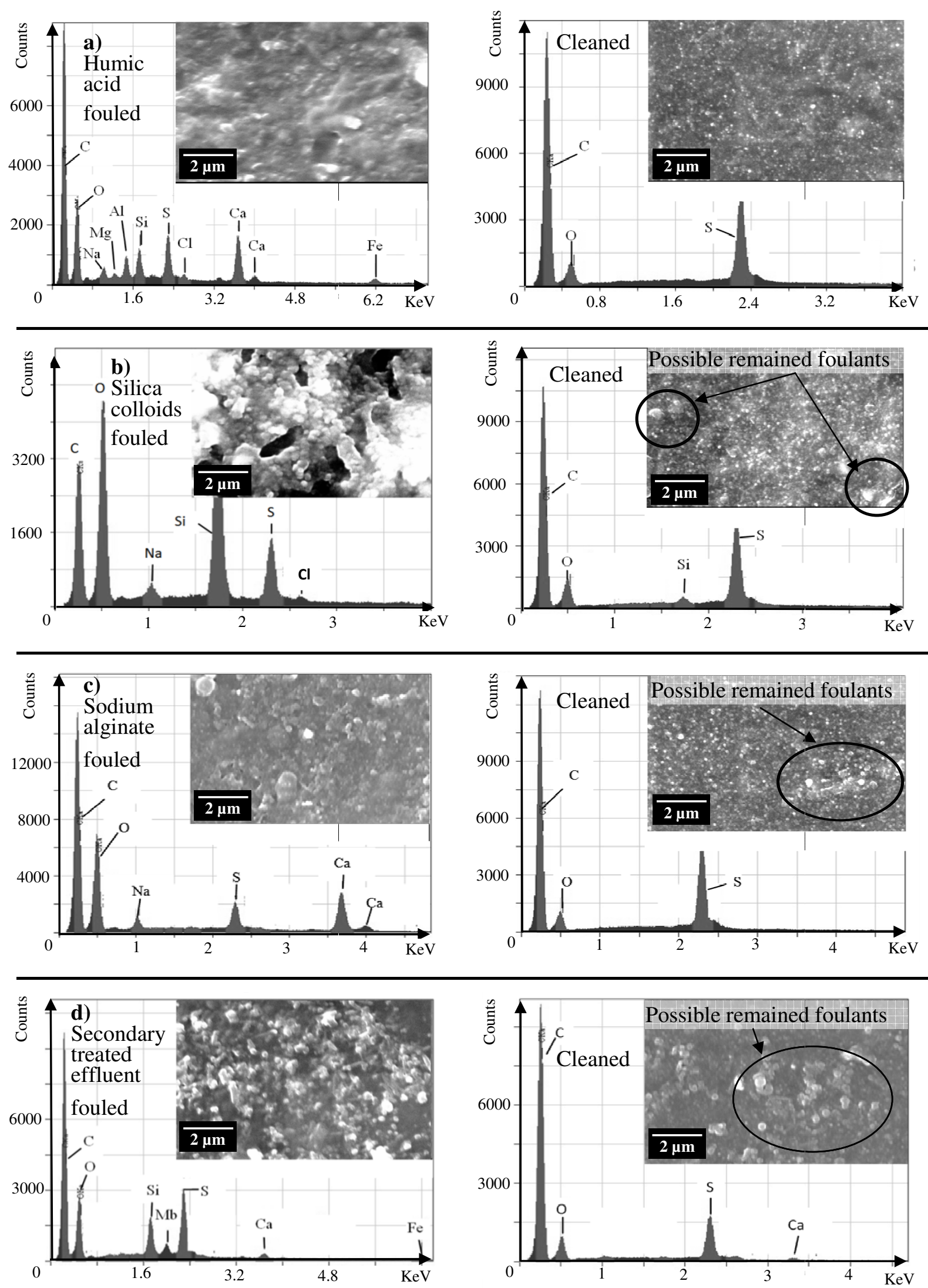
Figure 4: SEM-EDS images of a) humic acid, c) silica colloidal, d) sodium alginate and c) secondary treated effluent fouled and, after two cycles of operation, cleaned NF270. Micrographs of fouled and chemically cleaned NF270 membrane samples were at 15,000 times magnification, $20 \mathrm{kV}$ and a spot size of $40 \mathrm{~nm}$. EDS was undertaken at 2,000 times magnification, at $15 \mathrm{kV}$ and a spot size of $55 \mathrm{~nm}$.

\subsubsection{Hydrophobicity}

In its virgin state, the NF270 membrane has a hydrophilic surface [32]. Once fouled, the membrane surface was covered with the foulant and the surface hydrophobicity of the fouled membrane reflects the hydrophobicity of the foulant itself [35]. Changes observed in the membrane surface hydrophobicity due to humic acids, sodium alginate and secondary treated effluent fouling are consistent with data previously reported by Fujioka et al. [27]. Silica colloids are quite hydrophilic due to their negatively charged silanol groups [36]. Therefore, while organic fouling resulted in significant hydrophobicisation of the membrane surface, no impact on the membrane hydrophobicity could be observed due to silica colloidal fouling.

It is noteworthy that following the two repetitive fouling-cleaning cycles, chemical cleaning could not restore the surface hydrophobicity of the NF270 membrane to its initial (virgin) condition (Figure 5), which is consistent with the literature [37]. Weiss et al. [37] observed a permanent increase in the surface hydrophobicity after several cycles of fouling and caustic cleaning of polyethersulphone and polysulphone UF-membranes. In fact, in this study, the hydrophobicity of the chemically cleaned membrane resembled the hydrophobicity of the fouled membrane. There are three possible explanations for this observation. Firstly, caustic chemical cleaning may result in a more hydrophobic membrane surface due to possible conformational modifications of the membrane polymeric matrix as a result of the harsh caustic cleaning regime. Secondly, the metal chelating reagents used in commercially available cleaning formulations may adsorb to the membrane matrix, rendering the membrane surface more hydrophobic. Indeed, in a previous study, Simon et al. [34] reported that exposing the NF270 membrane to the MC11 cleaning formulation could result in a slight increase in the surface hydrophobicity. This, however, cannot fully explain the increased membrane surface hydrophobicity after chemical cleaning observed in Figure 5. In fact, when Ludox HS30 silica colloids were used to simulate fouling, the contact angle of the membrane surface after chemical cleaning was $40^{\circ}$, which is only 
slightly higher than that of the virgin membrane. Consequently, the third possibility is the presence of organic foulant residues on the membrane surface, which can lead to a high hydrophobicity of the membrane surface after organic fouling and chemical cleaning. This premise is also consistent with SEM-EDS observations (Figure 4). It is noteworthy that different trends in membrane surface hydrophobicity due to fouling were also reported in other studies [12, 15]. The discrepancies between this study and that of other authors were probably caused by the difference in the physicochemical properties of the foulants and the initial hydrophobicity of the membranes.

Figure 5: Surface hydrophobicity of the fouled and, after two cycles of operation, cleaned NF270 membrane. Fouling and cleaning conditions were as in Figure 2 and 3, respectively. Error bars show standard deviation of five repetitive measurements. 


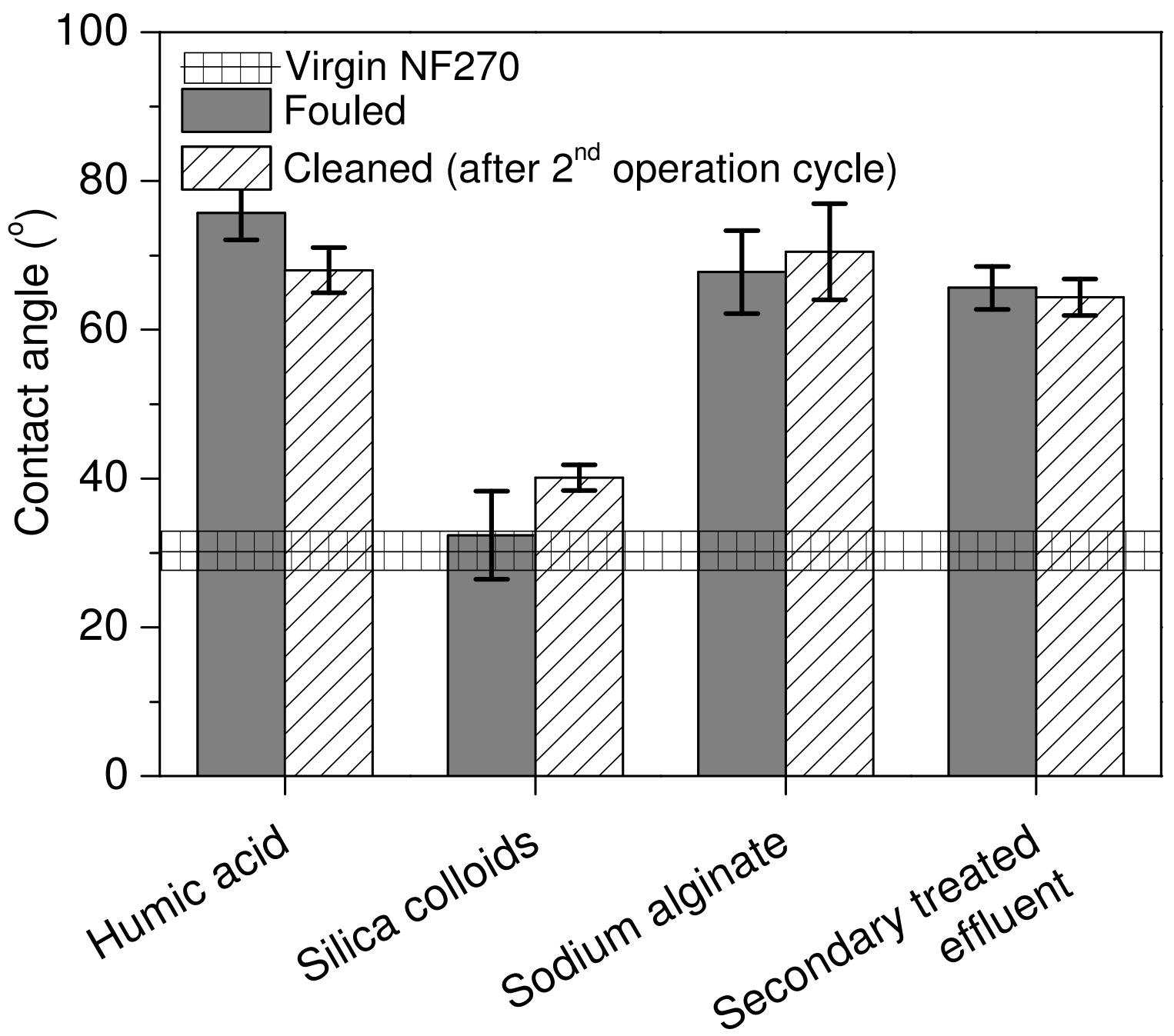

\subsection{3}

\section{Membrane Surface Charge}

The surface charge (or zeta potential) of the virgin NF270 membrane changed from being slightly positively charged below a $\mathrm{pH}$ of 3 to being significantly negatively charged as the solution $\mathrm{pH}$ increased (Figure 6). The dependence of the membrane zeta potential on the background solution $\mathrm{pH}$ could be attributed to the dissociation of carboxylic $(\mathrm{COOH})$ or amide $(\mathrm{NH})$ functional groups of the active skin layer [38]. Once fouled by organic foulants, the surface charge of the NF270 membrane became slightly more negatively charged. This observation is most evident with sodium alginate fouling (Figure 6), possibly because of the abundance carboxylic and hydroxyl functional groups in the sodium alginate molecule [7, 39]. Although the Ludox HS30 silica colloids have been reported to be very negatively charged [26, 39], silica colloidal fouling did not result in any discernible changes in the membrane surface charge. This is possibly due to 
the instability of the silica colloidal fouling layer, which could be removed by the high wall-shear stress during the streaming potential measurement [33]. Several previous studies have also found no significant impact of silica colloidal fouling on the membrane surface charge $[15,33]$.

Following two organic fouling and cleaning cycles, chemical cleaning could not return the surface charge of the NF270 membrane to its initial condition (Figure 6). In our previous studies, it has been demonstrated that exposing the clean NF270 membrane to various chemical cleaning reagents and formulations did not result in any discernible changes in the membrane surface charge $[19,34]$. Thus, the increase in membrane surface charge observed here is likely due to the presence of organic residuals on the membrane surface as discussed in section 3.2.1, which rendered the membrane surface not only more hydrophobic (section 3.2.2), but also more negatively charged. In contrast, no significant impact on the surface charge of the cleaned NF270 membrane was found when the Ludox HS30 was used to simulate silica colloidal fouling on the NF270 membrane. As discussed above, this is possibly because the silica colloidal fouling layer was unstable and could be readily removed by the high wall-shear stress during the zeta potential measurement. 


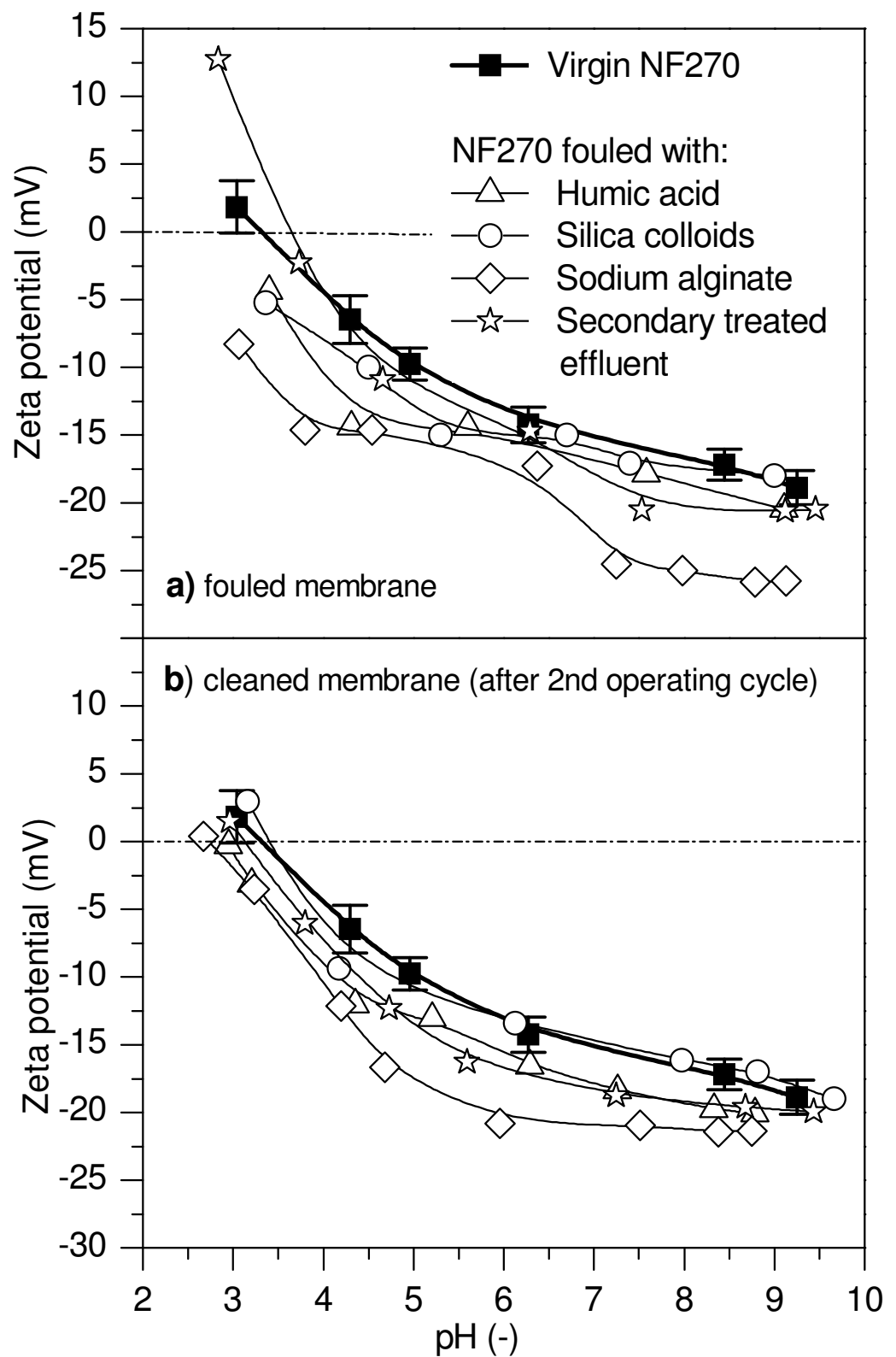

3.3

Impact on Rejection

Figure 6: Zeta potential of the a) fouled and, after two cycles of operation, b) cleaned NF270. Streaming potential measurement was conducted in $1 \mathrm{mM} \mathrm{KCl}$ at $20 \pm 1{ }^{\circ} \mathrm{C}$. Fouling and cleaning conditions were as in Figure 2 and 3, respectively. Error bars show the measured standard deviation of three repetitive measurements. 


\subsubsection{Conductivity}

The change in the rejection of inorganic salts (measured by conductivity) by the NF270 membrane due to repetitive fouling and chemical cleaning cycles is presented in Figure 7. It is noteworthy that conductivity rejection was measured at the same permeate flux to allow for a systematic comparison amongst the different membrane conditions. The influence of membrane fouling on the rejection of inorganic salts by a loose NF membrane could be determined by four distinctive mechanisms: pore blocking, the additional filtration effect of the fouling layer, changes in the membrane surface charge, and cake enhanced concentration polarisation (CECP) [10-11]. In good agreement with the literature, the interplay between these mechanisms can also be seen here. As previously shown in Figure 3, humic acid fouling resulted in the most severe decrease in membrane permeability due to pore blocking and the build-up of a humic acid fouling layer on the membrane surface. As a result, conductivity rejection increased considerably after the first fouling cycle (Figure 7). A small, but discernible increase in conductivity rejection after the membrane was first fouled with sodium alginate (which resulted in the second highest drop in membrane permeability) could also be observed. It is noteworthy that the increase in conductivity rejection due to humic acid and sodium alginate fouling observed here could also be attributed to some extent to the small increase in the membrane negative surface charge as reported in Figure 6. On the other hand, when the membrane was initially fouled with silica colloids or secondary treated effluent (which had a different ionic composition compared to that of the three model fouling solutions), the impact of fouling on conductivity rejection was insignificant. This is possibly because the CECP phenomenon could result in a decrease in the conductivity rejection, which counteracts the effect of pore blocking or the increase in membrane surface charge. CECP is particularly prevalent on colloidally fouled membranes, given the porous nature of the fouling layer $[11,40]$. It is also noteworthy that the use of Ludox HS30 silica colloids and secondary treated effluent resulted in a smaller decrease in membrane permeability in comparison to humic acid and sodium alginate.

Subsequent caustic cleaning removed most of the foulants from the membrane surface as reported in section 3.1. Caustic cleaning also led to an increase in the membrane porosity and thus in the membrane permeability (Figure 3). As a result, a significant decrease in conductivity rejection was observed immediately after caustic cleaning regardless of the previous fouling condition (Figure 7). The second fouling cycle again resulted in an increase in conductivity rejection, 
although, not as significant as the first one. Similarly, a decrease in conductivity rejection could also be observed after the second cleaning cycle. There appears to be a progressive modification of the membrane properties, leading to a gradual decrease in conductivity rejection after each cleaning cycle. This was observed when fouling was simulated using humic acid, sodium alginate, and silica colloids but not secondary treated effluent. Further studies are necessary to fully substantiate this observation.

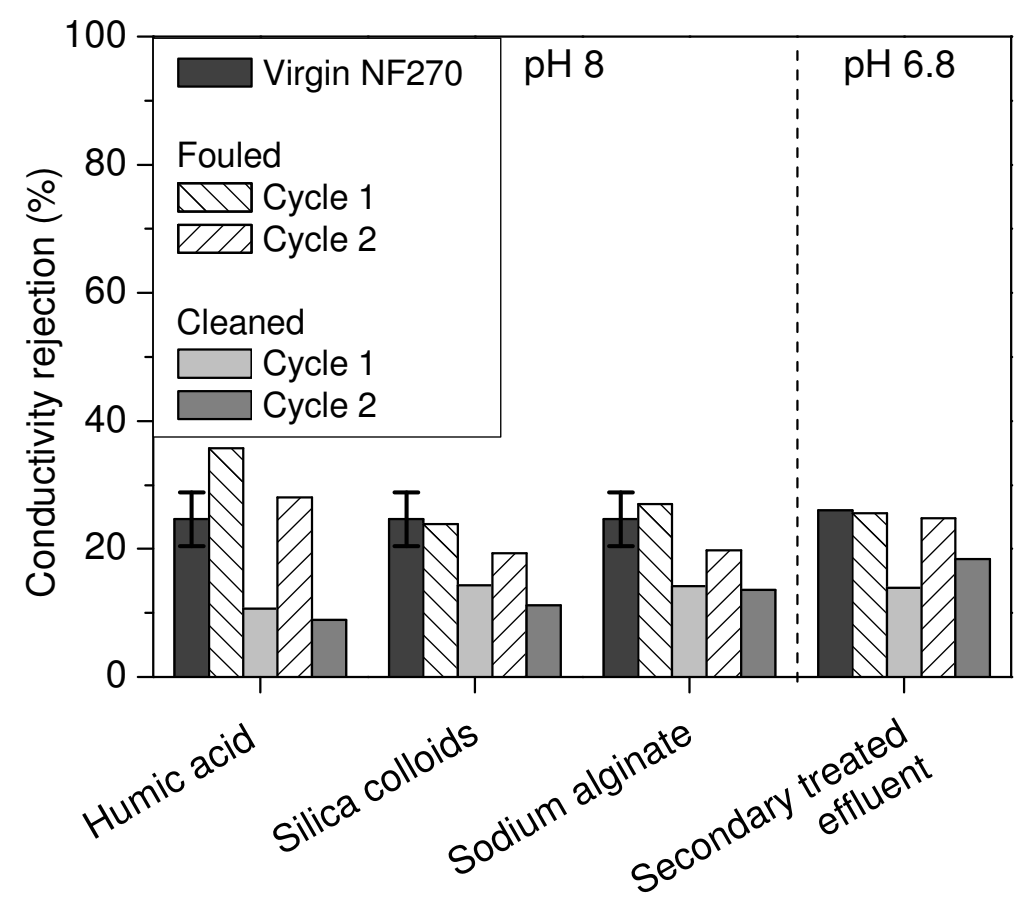

3.3.2

PhACs

Figure 7: Conductivity rejection of virgin, fouled and cleaned NF270. Fouling and cleaning conditions were as in Figure 2 and 3, respectively. Cross-flow velocity, permeate flux and temperature during the filtration were $23.6 \mathrm{~cm} / \mathrm{s}, 42 \mathrm{~L} / \mathrm{m}^{2} \mathrm{~h}$ and $20.0 \pm 0.1^{\circ} \mathrm{C}$, respectively.

Figure 8 shows the impact of two successive fouling and cleaning cycles on the rejection of carbamazepine and sulfamethoxazole by the NF270 membrane. It is noteworthy that the secondary treated effluent had a $\mathrm{pH}$ value of 6.8 , while that of the synthetic fouling solution (i.e. synthetic solutions containing a model foulant) had a $\mathrm{pH}$ value 8 . Solution $\mathrm{pH}$ may influence the rejection of ionisable organic compounds by changing slightly the surface charge of the membrane and the distribution between neutral and charged species at the vicinity of the compound $\mathrm{pK}_{\mathrm{a}}$ value (or the speciation of the compound). However, within an environmental $\mathrm{pH}$ 
range, carbamazepine is a non-ionisable and neutral organic compound. On the other hand, at $\mathrm{pH}$ above 5.81, which is the $\mathrm{pK}_{\mathrm{a}}$ value of sulfamethoxazole, the compound is negatively charged. Therefore, the difference in $\mathrm{pH}$ values in Figure 8 is not expected to significantly influence the rejection efficiency of either carbamazepine or sulfamethoxazole.

In general, the impact of two repetitive fouling and cleaning cycles on the rejection of carbamazepine is similar to that of conductivity. This is because the rejection of carmabazepine is governed exclusively by size exclusion. Membrane fouling by humic acid and secondary treated effluent caused pore blocking of the NF270 membrane, thus, carbamazepine rejection increased considerable after the first fouling cycle. Changes in the rejection of carbamazepine caused by silica colloidal and sodium alginate fouling were less apparent. As discussed in the previous section, the CECP phenomenon caused by silica colloidal and to some extent sodium alginate fouling may off-set the impact of pore blocking [14]. In good agreement with the results reported above, subsequent caustic cleaning rendered the NF270 membrane more open and thereby significantly increased the membrane permeability (Figure 3) and carbamazepine transport compared to that of the virgin NF270 membrane (Figure 8a). It is also noteworthy that the impact of fouling and cleaning on carbamazepine rejection was different amongst the two foulingcleaning cycles. This is possible due to the progressive modification of the membrane surface caused by each fouling or cleaning stage such as the adsorption of the negatively charged and hydrophobic foulants and/or the escalating impact of caustic cleaning on the membrane polymer. However, the exact mechanisms remain unknown and are subject for further investigation. In comparison to carbamazepine, sulfamethoxazole is negatively charged at both pH of 6.8 and 8 . Therefore, the rejection of sulfamethoxazole is governed pridominantly by electrostatic repulsion and size exclusion plays a less important role [41]. After the first fouling cycle, the rejection of the negatively charged sulfamethoxazole increased and varied only slightly as a response to further successive fouling and cleaning events. This permanent increase in sulfamethoxazole rejection is likely due to the adsorption of negatively charged foulants to the membrane polymer. This effect seems to be permanent, since chemical cleaning could not recover the membrane charge as previously discussed in section 3.2.3. It is noteworthy that the severe decrease in conductivity and carbamazepine rejection observed after each caustic cleaning cycle might not be permanent as also previously reported [34]. In this previous study, it was shown that dual step 
cleaning (i.e. caustic cleaning followed by acidic cleaning) could minimise the impact of caustic cleaning on neutral solute rejection by a NF270 membrane.

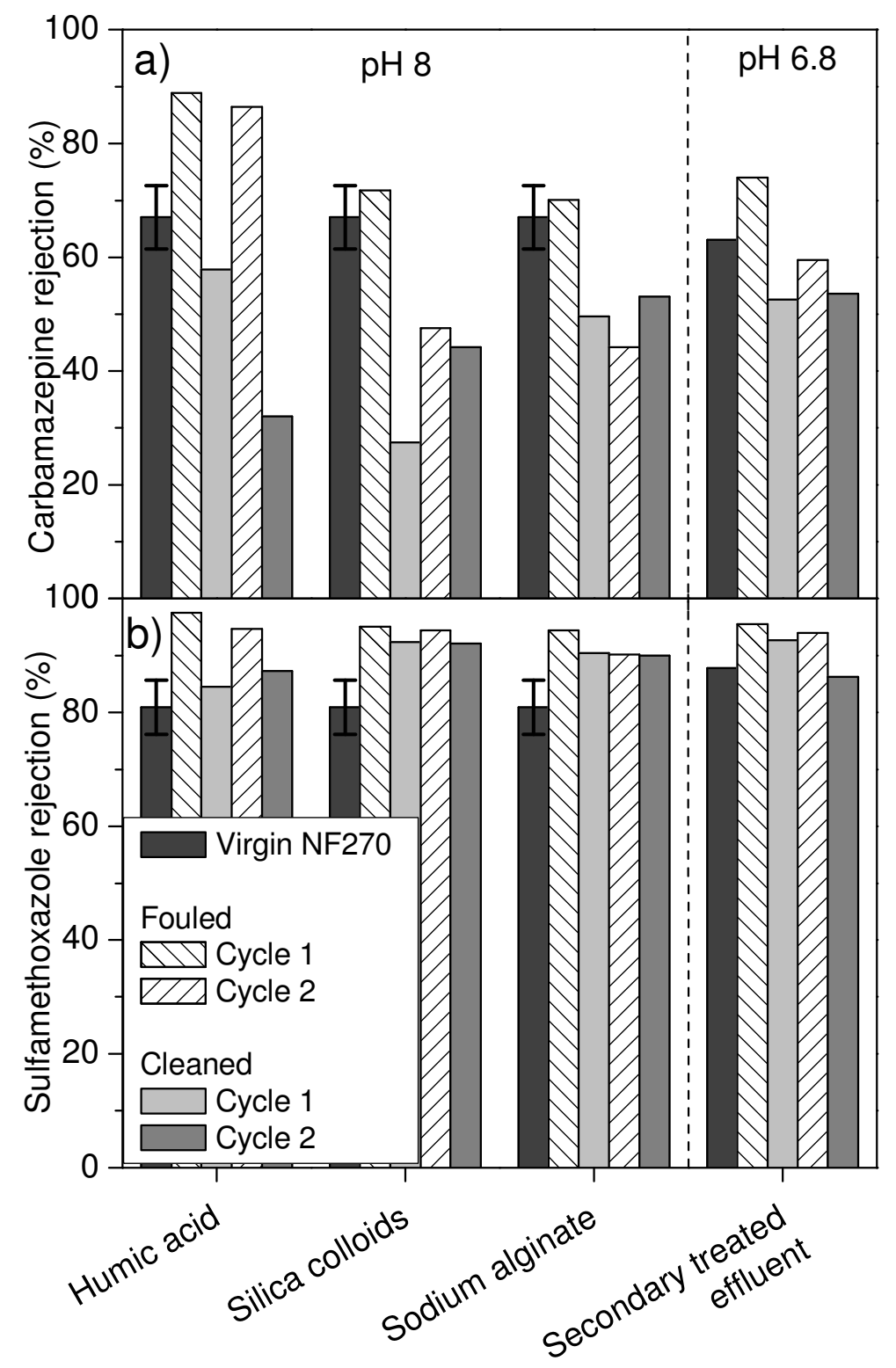

4.

\section{Conclusion}

Figure 8: a) Carbamazepine and b) sulfamethoxazole rejection of virgin, fouled and cleaned NF270. Fouling and cleaning conditions were as in Figure 2 and 3, respectively. Filtration conditions were as in Figure 7.

Repetitive membrane fouling and chemical cleaning resulted in notable changes in NF membrane surface properties and solute separation efficiency. The impact of membrane fouling on solute rejection was governed by pore blocking, modification of the membrane surface charged, and 
cake enhanced concentration polarisation in agreement with the literature. Caustic cleaning was effective in restoring the membrane permeability. However, SEM-EDS analysis revealed that the caustic cleaning procedure used in this study could not completely remove all foulants from the membrane surface. The remaining foulants could be responsible for the observed changes in the membrane surface hydrophobicity and zeta potential. Another significant mechanism governing the impact of chemical cleaning on solute rejection is the temporary enlargement of the membrane pores immediately after caustic cleaning. This resulted in a considerable decrease in the rejection of inorganic salts and the neutral carbamazepine after each caustic cleaning event. By contrast, caustic cleaning did not significantly influence the rejection of the negatively charged sulfamethoxazole. This is because the rejection of sulfamethoxazole was predominantly influenced by electrostatic interactions between the compound and the membrane negatively charged surface, and thus is not significantly influenced by any enlargement of membrane pores.

\section{Acknowledgements}

This study was supported by the Australian Research Council Discovery Project DP0985389. Dow Chemical and the IMDC Group BV are thanked for the provision of membrane samples and chemical cleaning formulations.

\section{References}

[1] Shannon, M.A., Bohn, P.W., Elimelech, M., Georgiadis, J.G., Marinas, B.J., and Mayes, A.M., Science and technology for water purification in the coming decades. Nature, 2008. 452(7185): p. 301-310.

[2] Wintgens, T., Melin, T., Schäfer, A., Khan, S., Muston, M., Bixio, D., and Thoeye, C., The role of membrane processes in municipal wastewater reclamation and reuse. Desalination, 2005. 178(1-3): p. 1.

[3] Lapworth, D.J., Baran, N., Stuart, M.E., and Ward, R.S., Emerging organic contaminants in groundwater: A review of sources, fate and occurrence. Environmental Pollution, 2012. 163(0): p. 287-303.

[4] Bolong, N., Ismail, A.F., Salim, M.R., and Matsuura, T., A review of the effects of emerging contaminants in wastewater and options for their removal. Desalination, 2009. 239(13): p. 229-246.

[5] Verliefde, A., Cornelissen, E., Amy, G., Van der Bruggen, B., and van Dijk, H., Priority organic micropollutants in water sources in Flanders and the Netherlands and assessment of removal possibilities with nanofiltration. Environmental Pollution, 2007. 146(1): p. 281-289. 
[6] Van der Bruggen, B., Mänttäri, M., and Nyström, M., Drawbacks of applying nanofiltration and how to avoid them: A review. Separation and Purification Technology, 2008. 63(2): p. 251-263.

[7] Hong, S. and Elimelech, M., Chemical and physical aspects of natural organic matter (NOM) fouling of nanofiltration membranes. Journal of Membrane Science, 1997. 132(2): p. 159-181.

[8] Verliefde, A.R.D., Cornelissen, E.R., Heijman, S.G.J., Petrinic, I., Luxbacher, T., Amy, G.L., Van der Bruggen, B., and Van Dijk, J.C., Influence of membrane fouling by (pretreated) surface water on rejection of pharmaceutically active compounds (PhACs) by nanofiltration membranes. Journal of Membrane Science, 2009. 330(1-2): p. 90-103.

[9] Nghiem, L.D. and Hawkes, S., Effects of membrane fouling on the nanofiltration of trace organic contaminants. Desalination, 2009. 236(1-3): p. 273-281.

[10] Nghiem, L.D. and Hawkes, S., Effects of membrane fouling on the nanofiltration of pharmaceutically active compounds (PhACs): Mechanisms and role of membrane pore size. Separation and Purification Technology, 2007. 57(1): p. 176-184.

[11] Nghiem, L.D., Espendiller, C., and Braun, G., Influence of organic and colloidal fouling on the removal of sulphamethoxazole by nanofiltration membranes. Water Science and Technology, 2008. 58(1): p. 163-169.

[12] Bellona, C., Marts, M., and Drewes, J.E., The effect of organic membrane fouling on the properties and rejection characteristics of nanofiltration membranes. Separation and Purification Technology, 2010. 74(1): p. 44-54.

[13] Ng, H.Y. and Elimelech, M., Influence of colloidal fouling on rejection of trace organic contaminants by reverse osmosis. Journal of Membrane Science, 2004. 244(1-2): p. 215-226.

[14] Nghiem, L.D., Coleman, P.J., and Espendiller, C., Mechanisms underlying the effects of membrane fouling on the nanofiltration of trace organic contaminants. Desalination, 2010. 250(2): p. 682-687.

[15] Xu, P., Drewes, J.E., Kim, T.U., Bellona, C., and Amy, G., Effect of membrane fouling on transport of organic contaminants in NF/RO membrane applications. Journal of Membrane Science, 2006. 279(1-2): p. 165-175.

[16] Agenson, K.O. and Urase, T., Change in membrane performance due to organic fouling in nanofiltration (NF)/reverse osmosis (RO) applications. Separation and Purification Technology, 2007. 55(2): p. 147.

[17] Al-Amoudi, A., Williams, P., Al-Hobaib, A.S., and Lovitt, R.W., Cleaning results of new and fouled nanofiltration membrane characterized by contact angle, updated DSPM, flux and salts rejection. Applied Surface Science, 2008. 254(13): p. 3983-3992.

[18] Al-Amoudi, A., Williams, P., Mandale, S., and Lovitt, R.W., Cleaning results of new and fouled nanofiltration membrane characterized by zeta potential and permeability. Separation and Purification Technology, 2007. 54(2): p. 234-240.

[19] Simon, A., Price, W.E., and Nghiem, L.D., Effects of chemical cleaning on the nanofiltration of pharmaceutically active compounds (PhACs) Separation and Purification Technology, 2012. 88: p. 208-215. 
[20] Liikanen, R., Yli-Kuivila, J., and Laukkanen, R., Efficiency of various chemical cleanings for nanofiltration membrane fouled by conventionally-treated surface water. Journal of Membrane Science, 2002. 195(2): p. 265-276.

[21] Košutić, K. and Kunst, B., RO and NF membrane fouling and cleaning and pore size distribution variations. Desalination, 2002. 150(2): p. 113-120.

[22] Wei, X., Wang, Z., Fan, F., Wang, J., and Wang, S., Advanced treatment of a complex pharmaceutical wastewater by nanofiltration: Membrane foulant identification and cleaning. Desalination, 2010. 251(1-3): p. 167-175.

[23] Klüpfel, A.M. and Frimmel, F.H., Nanofiltration of river water -- fouling, cleaning and micropollutant rejection. Desalination, 2009. 250(3): p. 1005-1007.

[24] Nghiem, L.D., Schäfer, A.I., and Elimelech, M., Removal of Natural Hormones by Nanofiltration Membranes: $\square$ Measurement, Modeling, and Mechanisms. Environmental Science \& Technology, 2004. 38(6): p. 1888-1896.

[25] Dow Chemicals, FILMTEC NF270-400 Nanofiltration Element. 2011; Available from: http://www.lenntech.com/Data-sheets/Dow-Filmtec-NF270-400.pdf.

[26] Boussu, K., Belpaire, A., Volodin, A., Van Haesendonck, C., Van der Meeren, P., Vandecasteele, C., and Van der Bruggen, B., Influence of membrane and colloid characteristics on fouling of nanofiltration membranes. Journal of Membrane Science, 2007. 289(1-2): p. 220230 .

[27] Fujioka, T., Khan, S.J., McDonald, J.A., Henderson, R.K., Poussade, Y., Drewes, J.E., and Nghiem, L.D., Effects of membrane fouling on N-nitrosamine rejection by nanofiltration and reverse osmosis membranes. Journal of Membrane Science, 2013. 427(0): p. 311-319.

[28] Floclean MC 11, Product Information. 2012; Available from: http://www.kebansu.com/media/data/013-2-FLOCLEAN-MC11-10-2011.pdf.

[29] Al-Amoudi, A. and Lovitt, R.W., Fouling strategies and the cleaning system of NF membranes and factors affecting cleaning efficiency. Journal of Membrane Science, 2007. 303(12): p. 4-28.

[30] Li, Q. and Elimelech, M., Organic Fouling and Chemical Cleaning of Nanofiltration Membranes: $\square$ Measurements and Mechanisms. Environmental Science \& Technology, 2004. 38(17): p. 4683-4693.

[31] Dow Chemicals, Cleaning Steps. 2012; Available from: http://www.dowwaterandprocess.com/support training/literature_manuals/filmtec manual.htm.

[32] Mänttäri, M., Pekuri, T., and Nyström, M., NF270, a new membrane having promising characteristics and being suitable for treatment of dilute effluents from the paper industry. Journal of Membrane Science, 2004. 242(1-2): p. 107-116.

[33] Simon, A., Price, W.E., and Nghiem, L.D., Implications of membrane fouling toward the removal of the pharmaceutical sulfamethoxazole by nanofiltration processes. Journal of Zhejiang University-SCIENCE A, 2011. 12(8): p. 575-582.

[34] Simon, A., Price, W.E., and Nghiem, L.D., Influence of formulated chemical cleaning reagents on the surface properties and seperation efficiency of nanofiltration membranes. Journal of Membrane Science, 2013. 432: p. 78-82. 
[35] Nghiem, L.D. and Coleman, P.J., NF/RO filtration of the hydrophobic ionogenic compound triclosan: Transport mechanisms and the influence of membrane fouling. Separation and Purification Technology, 2008. 62(3): p. 709-716.

[36] Nalaskowski, J., Drelich, J., Hupka, J., and Miller, J.D., Adhesion between Hydrocarbon Particles and Silica Surfaces with Different Degrees of Hydration As Determined by the AFM Colloidal Probe Technique. Langmuir, 2003. 19(13): p. 5311-5317.

[37] Weis, A., Bird, M. R., The Influence of Multiple Fouling and Cleaning Cycles upon the Membrane Processing of Lignosulphonates. Food and Bioproducts Processing, 2001. 79(3): p. 184-187.

[38] Childress, A.E. and Elimelech, M., Relating Nanofiltration Membrane Performance to Membrane Charge (Electrokinetic) Characteristics. Environmental Science \& Technology, 2000. 34(17): p. 3710-3716.

[39] Xiao, K., Wang, X., Huang, X., Waite, T.D., and Wen, X., Combined effect of membrane and foulant hydrophobicity and surface charge on adsorptive fouling during microfiltration. Journal of Membrane Science, 2011. 373(1-2): p. 140-151.

[40] Hoek, E.M.V. and Elimelech, M., Cake-enhanced concentration polarization: A new fouling mechanism for salt-rejecting membranes. Environmental Science \& Technology, 2003. 37(24): p. 5581-5588.

[41] Nghiem, L.D., Schäfer, A.I., and Elimelech, M., Pharmaceutical Retention Mechanisms by Nanofiltration Membranes. Environmental Science \& Technology, 2005. 39(19): p. 7698-7705. 